\title{
Desenvolvimento ponderal e biométrico de cabritos lactentes com acesso ao creep feeding em diferentes idades
}

\author{
Performance in vivo and biometric of goatling infant with access creep feeding at \\ different ages
}
BORGES, Gisele Daiane Silveira ${ }^{1 *}$; MACEDO, Vicente de Paulo²; BAIFFUS, Franciele Silveira Borges ${ }^{3}$; ATOJI, Katia²; HILL, João Ari Gualberto ${ }^{4}$; BATISTA, Rafael ${ }^{1}$; BIANCHI, Anderson Elias ${ }^{1}$; ORTIZ, Sidney ${ }^{1}$

\author{
${ }^{1}$ Universidade Tecnológica Federal do Paraná, Programa de Pós-Graduação em Zootecnia, Dois Vizinhos, \\ Paraná, Brasil. \\ ${ }^{2}$ Universidade Tecnológica Federal do Paraná, Departamento de Zootecnia, Dois Vizinhos, Paraná, Brasil. \\ ${ }^{3}$ Secretaria da Educação do Paraná, Coronel Vivida, Paraná, Brasil. \\ ${ }^{4}$ Instituto Agronômico do Paraná, Estação experimental de Pato Branco, Pato Branco, Paraná, Brasil. \\ *Endereço para correspondência: giseleborges@ zootecnista.com.br.
}

\section{RESUMO}

Objetivou-se avaliar o efeito da disponibilidade de creep feeding por diferentes períodos de tempo sobre o ganho de peso, peso a desmama e as medidas biométricas corporais de cabritos mestiços da raça Bôer. Foram utilizadas 12 cabras 7/8 Bôer, lactantes, e suas respectivas crias, distribuídas em três tratamentos, totalizando 27 cabritos, sendo nove por tratamento. O delineamento experimental utilizado foi $\mathrm{O}$ inteiramente casualizado, com três tratamentos e nove repetições por tratamento. Os tratamentos foram: acesso ao creep feeding do nascimento até os 70 dias de idade; acesso ao creep feeding a partir dos 20 dias até os 70 dias de idade; acesso ao creep feeding a partir dos 40 dias até os 70 dias de idade. Os dados foram coletados a cada 10 dias. A análise de variância e comparação entre médias foi realizada pelo teste Tukey. Os diferentes tratamentos possibilitaram diferenças de ganho de peso, peso vivo corporal, comprimento corporal, perímetro torácico e abdominal e altura de garupa. Não houve diferença no escore corporal e na altura de cernelha dos animais. Os melhores resultados foram observados em grupos submetidos aos maiores tempos de acesso à suplementação. Assim, indica-se esse tipo de suplementação durante a amamentação por pelo menos 50 dias, e demonstra a irrelevância do fornecimento de concentrado nos primeiros 20 dias de vida.

Palavras-chave: caprinos, crescimento, medidas, suplementação

\section{SUMMARY}

This study aimed to evaluate the effect of the availability of creep feeding for different periods of time on weight gain, weaning weight, body condition and biometric measurements bodily crossbred goats breed Boer. 12 goats were used 7/8 Boer, nursing mothers, and their offspring, in three treatments, totaling 27 kids, nine per treatment. The experimental design was a completely randomized design with three treatments and nine replications by treatment. The treatments were: access to creep feed from birth to 70 days of age; access to creep feed from 20 days until 70 days of age; access to creep feed from 40 days until 70 days of age. Data were collected every 10 days. The analysis of variance and comparison of means was performed by Tukey test. The different treatments possible differences in weight gain, body weight, body length, heart girth and abdominal and hip height. There was no difference in body condition and withers height and animals. The best results were observed in groups subjected to higher access times supplementation. Thus, we indicate this type of supplementation during breastfeeding for at least 50 days, and demonstrate the irrelevance of supply concentrated in the first 20 days of life.

Keywords: goats, growth, measures, supplementation 


\section{INTRODUÇÃO}

O principal período de crescimento animal é a fase de lactente. Para melhorar o desempenho nessa fase, o uso do creep feeding (comedouro privativo) é uma eficiente alternativa, possibilitando a correção de déficits nutricionais, aumentando assim a taxa de crescimento, a eficiência alimentar e o ganho de peso (GARCIA et al., 2003). Além disso, o correto manejo nutricional dos cabritos influencia também no desempenho das cabras, diminuindo o período de lactação, visto que os cabritos têm seu desenvolvimento acelerado, devolvendo a matriz mais cedo para a reprodução.

Para conhecer a capacidade de adaptação e desempenho dos animais diante das diferentes situações é fundamental avaliar tanto o peso ao nascer quanto $\mathrm{o}$ desenvolvimento ponderal dos animais, pois são características importantes quando se pretende iniciar um processo de seleção dos animais. Sendo assim, o desenvolvimento ponderal é o desenvolvimento em peso do animal do nascimento até fase de reprodução (JORGE et al., 2005).

Para se conhecer o potencial produtivo do animal é importante conhecer as suas medidas corporais. Com elas também é possível fazer a comparação entre rebanhos e a definição de padrões raciais, assim como indicar características como rendimento de carcaça e capacidade respiratória e digestiva. Essas medidas que vem sendo utilizadas nas avaliações de tamanho corporal também servem como base para conhecer as exigências nutricionais e a maturidade fisiológica do animal. Além disso, são pouco influenciadas pelo ambiente, e podem facilmente ser observadas. Dentre as mais importantes estão o comprimento corporal, altura de cernelha e de garupa, perímetro torácico e peso corporal (ROCHA et al., 2003).

Apesar de ser uma tecnologia de fácil manejo e simples implantação, e de diversas pesquisas comprovarem a importância da utilização do creep feeding na produção de pequenos ruminantes, ainda existem dúvidas sobre o tempo adequado de fornecimento dessa suplementação. Pois mesmo sendo decisivo para um bom desempenho animal, esse sistema acarreta custos à produção.

No intuito de eliminar algumas dúvidas ainda existentes sobre o tempo de suplementação adequado e seus resultados no desempenho animais, objetivou-se com este trabalho avaliar o efeito de diferentes períodos de acesso das crias ao creep feeding sobre o ganho de peso, peso ao desmame, condição corporal e as medidas biométricas corporais de cabritos mestiços da raça Bôer.

\section{MATERIAL E MÉTODOS}

O experimento foi conduzido na Fazenda Venson, no município de Honório Serpa, sudoeste do estado do Paraná, a uma altitude de $816 \mathrm{~m}$, latitude $26^{\circ} 08^{\prime} 27^{\prime \prime}$ Sul e longitude $52^{\circ}$ $23^{\prime} 13^{\prime \prime}$ Oeste. O período experimental foi de novembro de 2010 a fevereiro de 2011. Foram utilizados 27 cabritos lactentes, 15/16 Bôer juntamente com as matrizes, 12 cabras 7/8 Bôer (três cabras de gestação dupla e uma de gestação tripla). Os cabritos foram distribuídos em três tratamentos, sendo nove por tratamento. O delineamento experimental utilizado foi $\mathrm{o}$ delineamento inteiramente ao acaso, com três tratamentos e nove repetições. $\mathrm{Na}$ tabela 1 encontram-se as médias de 
escore corporal e peso vivo médio das cabras, em cada tratamento e período de avaliação.

Após o nascimento, os animais foram alojados em baias separadas por grupo conforme o tratamento a que foram submetidos, dispondo de comedouro, bebedouro, cocho para sal e fenil, sendo o piso da instalação do tipo "ripado suspenso". Anexo a cada baia foi instalado o creep feeding, contendo ração comercial peletizada, $(22 \% \mathrm{~PB}$ e $73 \%$ de NDT), em que o acesso dos cabritos foi liberado conforme a idade indicada em cada tratamento.

Tabela 1. Médias estimadas de peso vivo corporal e escore da condição corporal de cabras Bôer submetendo suas crias a diferentes períodos de acesso ao Creep feeding

\begin{tabular}{lcccc}
\hline Acesso ao Creep feeding & 70 dias & 50 dias & 30 dias & Média geral \\
\hline \multicolumn{7}{c}{ Peso Vivo Corporal $(\mathrm{Kg})$} \\
\hline Parto aos 20 dias & 67,43 & 67,272 & 70,65 & 68,45 \\
21 aos 40 dias & 66,82 & 67,013 & 63,82 & 65,88 \\
41 aos 70 dias & 68,44 & 68,436 & 59,34 & 64,73 \\
\hline \multicolumn{7}{c}{ Escore da Condição Corporal } \\
\hline Parto aos 20 dias & 2,33 & 2,34 & 3,06 & 2,58 \\
41 aos 40 dias 70 dias & 2,2 & 2,2 & 2,95 & 2,45 \\
\hline
\end{tabular}

O sistema de criação adotado foi $o$ semiextensivo, em que somente as cabras tinham acesso à pastagem de Papuã (Brachiaria plantaginea), das 7:00 às 11:30 e das 13:00 às 17:00 horas, além de receberem uma suplementação ( $1 \%$ do peso vivo) com concentrado $(18 \%$ de PB e $68 \%$ de NDT) e feno, durante o período noturno. Os animais foram monitorados quanto à infecção helmíntica através da técnica de Famacha, conforme Molento et al. (2004), sendo que nenhum precisou ser medicado durante $\mathrm{o}$ período experimental.

Os animais lactentes, com suas respectivas mães, foram divididos em três diferentes períodos de acesso ao creep feeding: período de 70 dias: cabritos com acesso ao creep feeding durante 70 dias (nascimento até $\mathrm{o}$ desmame); período de 50 dias: cabritos com acesso ao creep feeding durante 50 dias (20 dias de idade até o desmame); período de 30 dias: cabritos com acesso ao creep feeding durante 30 dias (40 dias de idade até o desmame).

Foi avaliado nos cabritos o peso vivo e as medidas biométricas ao nascimento e a cada 10 dias, até os 70 dias de vida. As medidas biométricas foram: comprimento de corpo (medido em linha reta da região da cartilagem escapular até a tuberosidade isquiática), perímetro torácico (na região da cernelha, passando pelas axilas, com leve pressão - área imediatamente caudal à escápula, passando pelo osso esterno e pelos processos espinhais das vértebras torácicas), perímetro abdominal (na região do abdômen, na linha da cicatriz umbilical), altura de cernelha (ponto mais alto da região escapular até o solo) e altura de garupa (da tuberosidade sacral do ílio até o solo) - (MELLO \& SCHMIDT, 2008; 
OLIVEIRA et al., 2009; REIS et al., 2008; YÁÑEZ, 2004).

As mensurações de perímetros e comprimento corporal foram realizadas com auxílio de fita métrica, e altura de cernelha e de garupa com uma régua de madeira graduada em centímetros, a qual foi adaptada uma haste (semelhante a um hipômetro) que deslizava pela superfície da mesma e posicionava-se exatamente acima do dorso do animal, ajustando a medida correta na régua e facilitando a leitura. Para pesagem dos animais utilizou-se balança graduada em $50 \mathrm{~g}$.

Os dados foram submetidos a análises de variância e comparação entre médias realizadas pelo teste de Tukey, considerando o nível de probabilidade de erro de $5 \%$ e, utilizando o Sistema de Análises Estatísticas e Genéticas (UFV, 2007), de acordo com o seguinte modelo:

$\mathrm{Y}_{\mathrm{ij}}=\mu+\mathrm{PAC}_{\mathrm{i}}+\mathrm{e}_{\mathrm{ij}}$

Sendo que: $Y_{\mathrm{ij}}$ : o valor observado da variável observada no indivíduo $\mathrm{j}$ recebendo o tratamento $\mathrm{i} ; \mu$ : a constante geral; $\mathrm{PAC}_{\mathrm{i}}$ : o efeito do período de acesso ao creep feeding i, i $=70 ; 50 ; 30$ dias; $\mathrm{e}_{\mathrm{ij}}: \mathrm{O}$ erro aleatório associado a cada observação.

$\mathrm{Na}$ avaliação dos dados, variáveis como peso ao nascer e ordem de parto, bem como todas as variáveis coletadas ao nascimento, foram utilizadas como covariáveis, o que elimina o efeito dessas sobre os resultados.

\section{RESULTADOS E DISCUSSÃO}

Quanto ao ganho médio diário, não se observou diferenças $(\mathrm{P}>0,05)$ entre os tratamentos nos primeiros 20 dias de observações, assim como dos 41 aos 70 dias de aleitamento. Dos 21 aos 40 dias de idade, os tratamentos 70 e 50 dias de acesso ao creep feeding apresentaram-se iguais estatisticamente, diferenciando do tratamento 30 dias, o qual apresentou os piores resultados para essa característica (Tabela 2). As médias gerais observadas (nascimento até os 70 dias) apresentam resultados estatísticos semelhantes ao encontrados dos 21 aos 40 dias.

Tabela 2. Médias estimadas e coeficiente de variação (CV) para ganho de peso médio diário, e peso vivo corporal de cabritos Bôer com acesso ao creep feeding em diferentes idades

\begin{tabular}{lccccc}
\hline \multicolumn{1}{c}{ Acesso ao Creep feeding } & 70 dias & 50 dias & 30 dias & Média geral & CV $(\%)$ \\
\hline & Ganho de Peso Médio Diário $(\mathrm{Kg})$ & & \\
\hline Nascimento aos 20 dias & 0,182 & 0,172 & 0,167 & 0,173 & 26,43 \\
21 aos 40 dias & $0,263^{\mathrm{a}}$ & $0,260^{\mathrm{a}}$ & $0,155^{\mathrm{b}}$ & 0,217 & 29,20 \\
41 aos 70 dias & 0,191 & 0,201 & 0,167 & 0,183 & 26,39 \\
Nascimento aos 70 dias & $0,209^{\mathrm{a}}$ & $0,210^{\mathrm{a}}$ & $0,164^{\mathrm{b}}$ & 0,194 & 20,40 \\
\hline \multicolumn{7}{c}{ Peso Vivo Corporal $(\mathrm{Kg})^{\mathrm{a}}$} \\
\hline Aos 20 dias & $9,100^{\mathrm{a}}$ & $8,500^{\mathrm{ab}}$ & $7,588^{\mathrm{b}}$ & 8,396 & 10,96 \\
Aos 40 dias & $14,377^{\mathrm{a}}$ & $13,700^{\mathrm{a}}$ & $10,700^{\mathrm{b}}$ & 12,925 & 13,67 \\
Aos 70 dias & $20,122^{\mathrm{a}}$ & $19,733^{\mathrm{a}}$ & $15,733^{\mathrm{b}}$ & 18,529 & 14,99 \\
\hline
\end{tabular}

Médias seguidas de letras distintas na mesma linha diferem pelo teste de Tukey a $5 \%$ de probabilidade $(\mathrm{P}<0,05)$.

*CV = coeficiente de variação. 
Estes resultados podem ser explicados pelo fato dos animais não ingerirem grande quantidade de alimento antes dos 20 dias de idade. Segundo Bôas et al. (2003), pequenos ruminantes têm necessidade de suplementação com alimentos sólidos apenas a partir dos 15 dias de vida. Sendo assim, para essa característica, seria mais vantajoso o fornecimento de suplementação a partir dos 20 dias de idade, evitando possíveis desperdícios de ração, podendo onerar o custo de produção.

Observando os resultados para ganho de peso médio diário durante os 70 dias de avaliação, a média vem de encontro com citado por Menezes et al. (2007), o qual indicam que animais dessa raça, em boas condições de manejo apresentam ganho médio de até $200 \mathrm{~g} /$ dia. Menezes et al. (2007), avaliando cabritos em diferentes idades com suplementação a partir da segunda semana de vida, observaram resultados inferiores em animais Bôer $1 / 2$ sangue e $3 / 4$. Sendo o ganho de peso médio de $0,114 \mathrm{~kg}$ e $0,112 \mathrm{~kg}$ do nascimento aos 30 dias de vida respectivamente, diferentemente do observado até os 20 dias no presente estudo $(0,173 \mathrm{~kg})$.

Para a característica peso vivo corporal, foi observado diferenças significativas aos 20 dias de idade entre o tratamento de 70 dias de suplementação e o tratamento com 30 dias. Sendo que o tratamento 50 dias não diferiu dos demais. Nas demais idades, essa diferença modifica-se, sendo que o tratamento 50 dias se equivale aos 70 dias e estes se diferenciam do tratamento 30 dias. Isso em consequência do início do fornecimento de aporte nutricional aos animais contidos no tratamento 50 dias, passando a desempenhar melhor do que os animais que não receberam ainda a suplementação.

Os últimos 30 dias de suplementação não foram suficientes para que os animais que passaram a receber suplementação nesse período se equiparassem aos demais quanto ao peso vivo corporal. A expressão do peso vivo corporal está de encontro com o ganho de peso médio diário, não observando diferenças entre os tratamentos de maiores períodos de suplementação. Assim é possível concluir que estes animais foram favorecidos pela ingestão de alimentos sólidos dos 20 dias de vida até os 40 dias, fato que não ocorreu no terceiro tratamento.

Os tratamentos 70 e 50 dias apresentaram peso vivo corporal médio aproximadamente $18 \%$ superior ao tratamento 30 dias, durante 70 dias de avaliação. Esses resultados vêm de encontro com os informados por Taylor \& Field (1999), os quais informam que o creep feeding possibilita um aumento de peso entre 10 a $30 \%$, em relação a animais sem acesso a essa suplementação.

Os resultados para peso vivo corporal aos 70 dias de idade nos tratamento $70 \mathrm{e}$ 50 dias, corroboram com o informado por Lôbo (2003), o qual indica que caprinos Bôer devem ser desmamados com aproximadamente $20,4 \mathrm{~kg}$ de peso vivo. Assim é possível afirmar que a disponibilização do creep feeding por pelo menos 50 dias na fase lactente possibilita o desmame com peso vivo corporal adequado, visando um sistema de produção de carne eficiente.

Algumas medidas vêm sendo utilizadas na avaliação do tamanho corporal, servindo também como base para conhecer as exigências nutricionais e a maturidade fisiológica do animal. Essas medidas são pouco influenciadas pelo ambiente, e podem facilmente ser observadas. Dentre as mais importantes estão o comprimento corporal, altura de cernelha e de garupa, assim como o perímetro torácico e peso corporal (ROCHA et al., 2003). Segundo 
Pacheco \& Quirino (2008), a reserva de gordura corporal não é suficiente para definir o peso do animal, sabendo que um animal magro pode ter peso maior que um gordo, desde que apresente maior estatura.

Em relação às médias encontradas neste trabalho, todas as medidas biométricas dos cabritos lactentes apresentaram diferenças $(\mathrm{P}<0,05)$ entre pelo menos dois tratamentos, com exceção da medida de altura de cernelha, a qual não apresentou diferença $(\mathrm{P}>0,05)$ entre nenhum tratamento, e nenhum período de avaliação. Essa semelhança pode ser explicada pela uniformidade do rebanho, e boa qualidade genética dos animais (Tabela 3 ).

Tabela 3. Médias estimadas e coeficiente de variação (CV) para comprimento do corpo, perímetro torácico, perímetro abdominal, altura de cernelha e altura de garupa de cabritos Bôer com acesso ao creep feeding em diferentes idades

\begin{tabular}{|c|c|c|c|c|c|}
\hline Acesso ao Creep feeding & 70 dias & 50 dias & 30 dias & Média geral & $\mathrm{CV}(\%)^{*}$ \\
\hline \multicolumn{6}{|c|}{ Comprimento Corporal $(\mathrm{cm})$} \\
\hline Nascimento aos 20 dias & 38,11 & 37,33 & 37,66 & 37,70 & 4,60 \\
\hline 21 aos 40 dias & $43,33^{\mathrm{a}}$ & $42,66^{\mathrm{a}}$ & $40,00^{\mathrm{b}}$ & 41,99 & 4,67 \\
\hline 41 aos 70 dias & $49,88^{\mathrm{a}}$ & $49,33^{\mathrm{a}}$ & $45,66^{\mathrm{b}}$ & 48,29 & 5,02 \\
\hline \multicolumn{6}{|c|}{ Perímetro Torácico $(\mathrm{cm})$} \\
\hline Nascimento aos 20 dias & $48,88^{\mathrm{a}}$ & $47,33^{\mathrm{a}}$ & $44,66^{\mathrm{b}}$ & 46,95 & 4,00 \\
\hline 21 aos 40 dias & $55,66^{\mathrm{a}}$ & $55,33^{\mathrm{a}}$ & $51,11^{\mathrm{b}}$ & 54,03 & 3,84 \\
\hline 41 aos 70 dias & $63,11^{\mathrm{a}}$ & $61,88^{\mathrm{a}}$ & $58,00^{\mathrm{b}}$ & 60,99 & 4,61 \\
\hline \multicolumn{6}{|c|}{ Perímetro Abdominal (cm) } \\
\hline Nascimento aos 20 dias & $53,88^{\mathrm{a}}$ & $53,00^{\mathrm{a}}$ & $49,44^{\mathrm{b}}$ & 52,10 & 5,24 \\
\hline 21 aos 40 dias & $66,22^{\mathrm{a}}$ & $65,11^{\mathrm{a}}$ & $59,44^{\mathrm{b}}$ & 63,59 & 6,98 \\
\hline 41 aos 70 dias & $76,22^{\mathrm{a}}$ & $75,22^{\mathrm{ab}}$ & $71,44^{\mathrm{b}}$ & 74,29 & 4,85 \\
\hline \multicolumn{6}{|c|}{ Altura de Cernelha $(\mathrm{cm})$} \\
\hline Nascimento aos 20 dias & 36,61 & 41,11 & 38,11 & 38,61 & 17,83 \\
\hline 21 aos 40 dias & 45,66 & 44,88 & 43,11 & 44,55 & 4,42 \\
\hline 41 aos 70 dias & 49,22 & 49,11 & 47,22 & 48,51 & 3,82 \\
\hline \multicolumn{6}{|c|}{ Altura de Garupa $(\mathrm{cm})$} \\
\hline Nascimento aos 20 dias & 41,72 & 41,38 & 39,55 & 40,88 & 4,47 \\
\hline 21 aos 40 dias & $47,77^{\mathrm{a}}$ & $46,00^{\mathrm{ab}}$ & $44,33^{\mathrm{b}}$ & 46,03 & 5,20 \\
\hline 41 aos 70 dias & $51,61^{\mathrm{a}}$ & $51,77^{\mathrm{a}}$ & $49,11^{\mathrm{b}}$ & 50,83 & 2,75 \\
\hline
\end{tabular}

Médias seguidas de letras distintas na mesma linha diferem pelo teste de Tukey a 5\% de probabilidade $(\mathrm{P}<0,05)$.

$\mathrm{CV}=$ coeficiente de variação.

As informações de altura de cernelha descritas neste trabalho ratificam as informações prestadas por Lima et al. (1989), que relatam a baixa correlação genética entre esta variável e a profundidade torácica, indicando ainda que os genes que definem o crescimento são diferentes dos que determinam as condições para peso. Os mesmos autores afirmam que na espécie bovina, para obter bom peso não é suficiente ter boa estatura, necessitando também dorso comprido, peito amplo, profundidade torácica, entre outras características que apresentem altas correlações genéticas com o peso animal.

Para a variável altura de garupa não houve diferença $(\mathrm{P}>0,05)$ para os três tratamentos nos primeiros 20 dias de vida dos animais. Porém, observam-se diferenças $(\mathrm{P}<0,05)$ a partir dos 21 dias. 
No período de 21 a 40 dias de vida, o tratamento 70 dias de creep feeding apresenta médias semelhantes ao tratamento 50 dias, e difere-se do tratamento 30 dias.

Esse mesmo comportamento é repetido dos 41 aos 70 dias de vida. O diferencial é que dos 21 aos 40 dias, os tratamentos 50 e 30 dias não diferem estatisticamente, porém passam a serem diferentes após os 41 dias de aleitamento. Tais resultados vêm de encontro com o esperado, em razão do fornecimento de suplementação, o qual teoricamente ofereceria um melhor aporte nutricional para o desenvolvimento ósseo, resultando em maior crescimento. Segundo Ribeiro (1998), a altura da garupa deve se apresentar o mais semelhantemente possível ao da cernelha, possibilitando ao animal uma boa proporção corporal, característica encontrada nos animais avaliados.

Ao comparar os animais avaliados neste trabalho com cabritos da raça Anglonubiana, pesquisado por Oliveira et al. (2009), é possível verificar a semelhança de altura de garupa entre as raças. Aos 30 dias de idade, os animais da raça Anglonubiana apresentaram médias, nos machos, de $44,1 \mathrm{~cm}$, e fêmeas de 41,5cm. Aos 60 dias de idade essa semelhança se acentua, sendo que os animais da raça Anlgonubiana apresentaram $49,8 \mathrm{~cm}$ em machos e $46,8 \mathrm{~cm}$ em fêmeas e, nos animais da raça Bôer constatou-se média de $50,83 \mathrm{~cm}$ para os três tratamentos.

As medidas de comprimento corporal não apresentaram diferenças $(\mathrm{P}>0,05)$ entre os tratamentos no primeiro período de avaliação (nascimento aos 20 dias), porém apresentaram diferenças nos demais períodos, sendo que o tratamento 30 dias foi inferior aos tratamentos 70 e 50 dias. É possível observar que o maior período de acesso ao creep feeding influenciou também nessa característica. Outro fator importante é que nos 20 primeiros dias o acesso ao creep feeding do tratamento 70 dias não teve influência no desenvolvimento corporal, outro dado relevante para a afirmação de que nesses primeiros dias os animais não tem ingestão considerável de alimentos sólido.

Os animais avaliados nos tratamentos 70 e 50 dias apresentaram desenvolvimento de comprimento corporal semelhante durante todo o período experimental. Esses resultados indicam que essa fonte alimentar influencia no crescimento de animais nessa fase de desenvolvimento, e que os animais passaram a ingerir mais alimento com o decorrer da idade. Com isso podemos incluir o fator nutrição à teoria de Landin et al. (2007) de que afirmam que essas medidas são influenciadas pelo genótipo, idade e peso do animal.

Medidas de perímetro torácico em caprinos têm como principal objetivo estimar a capacidade respiratória e vascular do animal, o que está relacionado com a capacidade produtiva (SANTANA et al., 2001). Por ser um parâmetro importante na caracterização do desempenho produtivo e das características de carcaça, é fundamental para caprinos especializados na produção de carne, apresentar um bom perímetro torácico.

Quanto aos resultados obtidos no presente trabalho, as medidas de tórax apresentaram diferenças $(\mathrm{P}<0,05)$ em todos os períodos avaliados entre $\mathrm{o}$ tratamento 30 dias e os demais, em que os animais submetidos a esse sempre apresentaram perímetros menores. Já os tratamentos 70 e 50 dias não diferiram entre si, apresentando resultados muito semelhantes em quase todas as avaliações. Esses dados confirmam que 
a suplementação melhora o desempenho dos animais, também expressa a afirmação de que até os 20 dias de idade o crescimento em função da ingestão de sólidos é pouco expressiva.

Os resultados vem de encontro com o informado por Costa et al. (2008), os quais afirmam que o perímetro torácico, juntamente com a condição corporal, refletem o nível alimentar da dieta fornecida aos animais.

Essa medida biométrica possibilitou expressar a superioridade dos animais da raça Bôer para a produção de carne, perante animais de dupla aptidão ou para leite, como podemos observar comparando os dados com os de Oliveira et al. (2009). Nesse caso os cabritos Anglonubianos tiveram resultados inferiores em todas as idades. Essa medida é diretamente influenciada pela estrutura óssea e muscular do animal, e pela deposição de tecido adiposo, na região do esterno, principalmente (YÁÑEZ et al., 2004). Comparando os pequenos ruminantes, Sousa et al. (2009a), pesquisando ovinos Santa Inês e caprinos mestiços Boer, verificaram que os ovinos apresentaram perímetro torácico maior do que os caprinos.

Souza et al (2009b), trabalhando com ovinos Santa Inês, Texel, Dorper e Ille de France, relatam que o perímetro torácico apresenta equações de mais altos coeficientes de determinação, baixos coeficientes de variação e produz resultados altamente significativos. $\mathrm{O}$ mesmo comportamento pode ser observado nos resultados encontrados no presente trabalho.

Quanto ao perímetro abdominal, também nota-se diferenças $(\mathrm{P}<0,05)$ entre os tratamentos 70 e 50 dias, em relação ao tratamento 30 dias, do nascimento até os 40 dias. Porém, a partir dos 41 dias observa mudanças, pois os animais constituintes do tratamento 30 dias tiveram um aumento médio de perímetro abdominal considerável, tornando-se igual ao tratamento 50 dias. Essa semelhança pode ser explicada pelo início do fornecimento de suplementação a partir dos 40 dias para os animais contidos nesse tratamento. Podemos assim afirmar que a quantidade de alimento ingerido influencia diretamente no perímetro de abdômen.

Os resultados de perímetro torácico vêm de encontro com o relatado por Mello \& Schmidt (2008), afirmando que o perímetro abdominal é capaz de indicar a capacidade ingestiva do indivíduo, apresentando alta correlação com o volume ruminal. Nesse caso, a ingestão de leite somado ao consumo de ração resulta em maior volume a essa região.

Os caprinos apresentam uma particularidade quando comparados aos ovinos, de que o principal depósito de gordura é a cavidade abdominal, visto que apresentam uma capa de gordura subcutânea muito fina. As vísceras e o abdômen depositam cerca de 50 a $60 \%$ da gordura total do corpo desses animais (GRANDE et al., 2003). O sistema estomacal dos caprinos é volumoso, suportando 20 a 30 litros, assim, quando repleto de alimento, essa área apresenta maior volume, consequentemente medindo maior perímetro (RIBEIRO, 1998).

Diante dos resultados obtidos, podemos afirmar que o mais indicado para um bom desempenho produtivo e melhores parâmetros biométricos em caprinos de corte é a utilização de creep feeding por pelo menos 50 dias. Observou-se também, que o fornecimento de suplementação aos cabritos de até 20 dias de idade não influenciou no desempenho produtivo dos mesmos. Sugerindo assim que o fornecimento de concentrado tenha início a partir dos 20 
Rev. Bras. Saúde Prod. Anim., Salvador, v.14, n.4, p.745-754 out./dez., 2013 http://www.rbspa.ufba.br ISSN 15199940

dias de idade, possibilitando a diminuição dos custos de produção.

\section{AGRADECIMENTOS}

Ao Senhor Vilmar Antônio Venson, proprietário da fazenda Venson, pela disponibilidade da estrutura e animais para a realização deste experimento.

\section{REFERÊNCIAS}

BÔAS, A.S.V.; ARRIGONI, M.B.; SILVEIRA, A.C.; COSTA, C.; CHARDULO, L.A.L. Idade a desmama e manejo alimentar na produção de cordeiros superprecoces. Revista Brasileira de Zootecnia, v.32, n.6, p.1969-1980, 2003.

COSTA, R.G.; ALMEIDA, C.C.; PIMENTA FILHO, E.C.; HOLANDA JUNIOR, E.V.; SANTOS, N.M.

Caracterização do sistema de produção caprino e ovino na região semi-árida do estado da Paraíba, Brasil. Archivos

Zootecnia, v.57, p.195-205, 2008.

GARCIA, C.A.; COSTA, C.; MONTEIRO, A.L.G.; NERES, M.A.; ROSA, G.J.M. Níveis de energia no desempenho e características da carcaça de cordeiros alimentados em creep feeding. Revista Brasileira de Zootecnia, v.32, n.6, p.1371-1379, 2003.

GRANDE, P.A.; ALCALDE, C.R.; MACEDO, F.A.F.; YAMAMOTO, S.M.; MARTINS, E.N. Desempenho e características de carcaça de cabritos da raça Saanen recebendo rações com farelo de glúten de milho e/ou farelo de soja. Acta Scientiarum, v.25, n.2, p.315-321, 2003.
JORGE, A.M.; ANDRIGHETTO, C.; CASTRO, V.S. Desenvolvimento ponderal de bubalinos da raça Murrah criados em pastagem de Brachiaria brizantha no Centro-Oeste do Estado de São Paulo, Brasil. Ciência rural, v.35, n.2, p.417-421, 2005.

LANDIN, A.V.; MARIANTE, A.S.; MCMANUS, C.; GUGEL, R.; PAIVA, S.R. Características quantitativas da carcaça, medidas morfométricas e suas correlações em diferentes genótipos de ovinos. Ciência Animal Brasileira, v.8, n.4, p.665-676, 2007.

LIMA, F.P.; BONILHA NETO, L.M.; RAZOOK, A.G.; PACOLA, L.J.; FIGUEIREDO, L.A.; PEIXOTO, A.M. Parâmetros genéticos em características morfológicas de bovinos Nelore.

Boletim de Indústria Animal, v.46, n.2, p.249-257, 1989.

LÔBO, R.N.B. Cruzamento industrial: quando e como fazer? In: SEMINÁRIO NORDESTINO DE PECUÁRIA, 7., 2003, Fortaleza. Anais... Fortaleza, 2003. v.5, p.81-96.

MELLO, F.A.; SCHMIDT, V. Caracterização biométrica de caprinos anglo-nubianos nascidos no Brasil, no período de 1993 a 2001. Archivos de Zootecnia, v.57, n.220, p.525-527, 2008.

MOLENTO, M.B.; TASCA, C.; GALLO, A.; FERREIRA, M.; BONONI, R.; STECCA, E. Método famacha como parâmetro clínico individual de infecção por "Haemonchus contortus" em pequenos ruminantes. Ciência Rural, v.34, n.4, p.1139-1145, 2004.

MENEZES, J.J.L.; GONÇALVES, H.C.; RIBEIRO, M.S.; RODRIGUES, L.; CAÑIZARES, G.I.L.; MEDEIROS, 
B.B.L.; GIASSETTI, A.P. Desempenho e medidas biométricas de caprinos de diferentes grupos raciais. Revista Brasileira de Zootecnia, v.36, n.3, p.635-643, 2007.

OLIVEIRA, D.F.; CRUZ, J.F.; CARNEIRO, P.L.S.; MALHADO, C.H.M.; RONDINA, D.; FERRAZ, R.C.N.; TEIXEIRA NETO, M.R. Desenvolvimento ponderal e características de crescimento de caprinos da raça anglonubiana criados em sistema semi-intensivo. Revista

Brasileira de Saúde e Produção Animal, v.10, p.256-265, 2009.

PACHECO, A.; QUIRINO, C.R. Estudo das características de crescimento em ovinos. Pubvet, v.2, n. 29,2008

REIS, G.L.; ALBUQUERQUE, F.H.M.A.R.; VALENTE, B.D.; MARTINS, G.A.; TEODORO, R.L.; FERREIRA, M.B.D.; MONTEIRO, J.B.N.; SILVA, M.A.; MADALENA, F.E. Predição do peso vivo a partir de medidas corporais em animais mestiços Holandês/Gir. Ciência Rural, v.38, n.3, p.778-783, 2008.

RIBEIRO, S.D.A. Caprinocultura: criação racional de caprinos. São Paulo: Nobel, 1998. 318p.

ROCHA, E.D.; ANDRADE, V.J; EUCLIDES FILHO, K.; NOGUEIRA, E.; FIGUEIREDO, G.R. Tamanho de vacas Nelore adultas e seus efeitos no sistema de produção de gado de corte. Arquivo Brasileiro de Medicina Veterinária e Zootecnia, v.55, n.4, p.474-9, 2003.

UNIVERSIDADE FEDERAL DE VIÇOSA - UFV. Sistema para análise estatística e genética- SAEG. Versão 9.1.
Viçosa: Fundação Arthur Bernardes, 2007.

SANTANA, A.F.; COSTA, G.B.; FONSECA, L.S. Correlações entre peso e medidas corporais em ovinos jovens da raça Santa Inês. Revista Brasileira de Saúde e Produção Animal, v.1, p.74-77, 2001.

SOUSA, W.H.; BRITO, E.A.; MEDEIROS, A.N.; CARTAXO, F.Q.; CEZAR, M.F.; CUNHA, M.G.G. Características morfométricas e de carcaça de cabritos e cordeiros terminados em confinamento. Revista Brasileira de Zootecnia, v.38, n.7, p.1340-1346, 2009a.

SOUZA, S.; LEAL, A.; BARIONI, C.; MATOS, A.; MORAIS, J.; ARAÚJO, M.; NETO, O.; SANTOS, A.; COSTA, R. Utilização de medidas biométricas para estimar peso vivo em ovinos. Asociación Latino Americana de Producción Animal, v.17, n.3, p.61-66, 2009.

TAYLOR, R.E.; FIELD, T.G. Beef production and management decisions. 3.ed. New Jersey: Prentice Hall, 1999. 714p.

YÁÑEZ, E.A.; RESENDE, K.T.; FERREIRA, A.C.D.; MEDEIROS, A.N.; SILVA SOBRINHO, A.G.; PEREIRA FILHO, J.M.; TEIXEIRA, I.A.M.A.; ARTONI, S.M.B. Utilização de medidas biométricas para predizer características da carcaça de cabritos Saanen. Revista Brasileira de Zootecnia, v.33, n.6, p.1564-1572, 2004.

Data de recebimento: 23/05/2013

Data de aprovação: 03/12/2013 